\title{
GDNF Selectively Protects Dopamine Neurons over Serotonin Neurons Against the Neurotoxic Effects of Methamphetamine
}

\author{
Wayne A. Cass \\ Department of Anatomy and Neurobiology, University of Kentucky College of Medicine, Lexington, Kentucky 40536
}

Repeated methamphetamine (METH) administration to animals can result in long-lasting decreases in striatal dopamine (DA) and serotonin (5-HT) levels. Glial cell line-derived neurotrophic factor (GDNF) has pronounced effects on dopaminergic systems in vivo, including partial neuroprotective effects against 6-hydroxydopamine and 1-methyl-4-phenyl-1,2,3,6tetrahydropyridine -induced lesions. The present study examined the ability of GDNF to prevent METH-induced reductions in potassium-evoked overflow of DA, and DA and 5-HT content, in striatum. GDNF $(10 \mu \mathrm{g})$ or vehicle was injected into the right striatum of anesthetized rats. Twenty-four hours later, the rats were injected four times at $2 \mathrm{hr}$ intervals with METH $(5 \mathrm{mg} / \mathrm{kg}$, s.c.) or saline. One week later, in vivo electrochemistry was used to monitor the overflow of DA evoked by local potassium application. Evoked overflow of DA was dramatically decreased in the striatum of METH-treated animals. GDNF prevented the reduction in evoked overflow of DA in the right striatum of the METH-treated animals. After each experiment, the animals were killed, and striatal DA and 5-HT levels determined by HPLC. The METH treatment produced significant decreases in both neurotransmitters. GDNF administration prevented the reduction in striatal DA levels on the treated side of the brain, whereas levels on the contralateral side were still decreased. In dose-response studies, $1 \mu \mathrm{g}$ of GDNF was as protective as 10 $\mu \mathrm{g}$, whereas $0.1 \mu \mathrm{g}$ was only partially protective. In contrast, $5-\mathrm{HT}$ levels were only minimally protected by previous administration of GDNF. These results suggest that GDNF can selectively protect DA neurons, compared with 5-HT neurons, against the neurotoxic effects of METH.

Key words: GDNF; methamphetamine; striatum; dopamine; serotonin; neurotrophic factor; in vivo electrochemistry; neurotoxicity
The repeated administration of methamphetamine (METH) can produce regionally specific changes in brain dopamine (DA) and serotonin (5-HT) systems. These changes include decreases in striatal DA and 5-HT content and uptake, as well as reductions in tyrosine hydroxylase and tryptophan hydroxylase activity (Seiden and Ricaurte, 1987; Axt et al., 1994; Gibb et al., 1994). Evidence of nerve terminal degeneration and gliosis also are found in the striatum (Lorez, 1981; Ricaurte et al., 1982; Bowyer et al., 1994; Pu and Vorhees, 1995). The time course for these changes is relatively long-lasting, and there are still decreases in striatal DA content 6 months after METH administration in monkeys and rats (Seiden et al., 1975/76; Bittner et al., 1981; Finnegan et al., 1982).

Glial cell line-derived neurotrophic factor (GDNF) has been found to exert potent effects on nigrostriatal DA neurons (Lin et al., 1993; Beck et al., 1995; Gash et al., 1995, 1996; Tomac et al., 1995; Hou et al., 1996; Martin et al., 1996). Injection of GDNF into the substantia nigra of rats can produce increased nigral DA levels, sprouting of tyrosine hydroxylase positive neurites toward the injection site, and increased DA turnover and tyrosine hydroxylase immunoreactivity in the ipsilateral striatum 3 weeks after a single injection (Hudson et al., 1995; however, see Beck et al., 1996). In rats unilaterally lesioned

\footnotetext{
Received May 30, 1996; revised Sept. 24, 1996; accepted Sept. 27, 1996.

This work was supported in part by the University of Kentucky Medical Center Research Fund. I thank Mr. Michael Dugan for his excellent technical assistance, Dr. Don M. Gash for his comments on this manuscript, and Synergen, Inc. (Boulder, $\mathrm{CO})$ for the generous gift of GDNF.

Correspondence should be addressed to Dr. Wayne A. Cass, Department of Anatomy and Neurobiology, MN 224 Chandler Medical Center, University of Kentucky, Lexington, Kentucky 40536-0084.

Copyright (C) 1996 Society for Neuroscience $0270-6474 / 96 / 168132-08 \$ 05.00 / 0$
}

with 6-hydroxydopamine (6-OHDA), GDNF markedly reduced apomorphine-induced rotational behavior and increased nigral DA levels and tyrosine hydroxylase-positive neurons on the lesioned side (Hoffer et al., 1994; Bowenkamp et al., 1995). In mice, GDNF can partially reverse the effects of 1-methyl-4phenyl-1,2,3,6-tetrahydropyridine (MPTP) on nigrostriatal DA neurons (Tomac et al., 1995).

GDNF also exhibits neuroprotective properties. When given 24 hr before 6-OHDA (Kearns and Gash, 1995) or soon afterward (Sauer et al., 1995), intranigral GDNF reduces degeneration of nigral DA neurons. GDNF administration can also reduce degeneration of mesencephalic DA neurons after transection of the medial forebrain bundle (Beck et al., 1995). When given intracerebrally to mice $24 \mathrm{hr}$ before MPTP, GDNF reduces loss of nigral DA neurons and attenuates decreases in nigral and striatal DA levels (Tomac et al., 1995). Taken together, the above studies suggest that GDNF has profound effects on both normal and lesioned nigrostriatal DA systems. However, the effects of GDNF on METH-induced damage to DA and 5-HT systems have not been examined previously.

In vivo electrochemistry can be used to monitor the dynamics of DA release and clearance with a high degree of temporal and spatial resolution (Wood et al., 1992; Cass et al., 1993; Garris and Wightman, 1994; Gratton and Wise, 1994; Cass and Gerhardt, 1995; Suaud-Chagny et al., 1995). In the present study, in vivo electrochemistry was used to investigate whether GDNF can prevent METH-induced changes in evoked overflow of DA in rat striatum. In addition, striatal levels of DA and 5-HT were measured to determine the extent of the lesion produced by METH and the ability of GDNF to prevent depletion of these transmitters. 


\section{MATERIALS AND METHODS}

Animals. Male Fischer-344 rats (Harlan Sprague Dawley, Indianapolis, IN) weighing 240-330 gm were used for all experiments. They were housed in groups of two to four under a $12 \mathrm{hr}$ light/dark cycle with food and water available ad libitum. All animal-use procedures were in strict accordance with National Institutes of Health Guide for the Care and Use of Laboratory Animals and were approved by the Animal Care and Use Committee at the University of Kentucky.

GDNF administration. Rats were anesthetized with sodium pentobarbital $(50 \mathrm{mg} / \mathrm{kg}$, i.p.) and placed into a stereotaxic frame. All surgery was performed using sterile instruments and aseptic conditions. The skull was exposed and a small hole drilled in the skull over the right striatum. Human recombinant GDNF $(10,1.0$, or $0.1 \mu \mathrm{g}$ in $2 \mu \mathrm{l}$ of vehicle solution) or $2 \mu \mathrm{l}$ of vehicle (10 mM citrate buffer with $150 \mathrm{~mm} \mathrm{NaCl}, \mathrm{pH} 5$ ) was injected into the right striatum $(1.2 \mathrm{~mm}$ anterior to bregma, $2.5 \mathrm{~mm}$ lateral from midline, $4.5 \mathrm{~mm}$ below the surface of the cortex) using a Hamilton syringe (26 gauge blunt tapered needle). The rate of injection was $0.2 \mu \mathrm{l} / \mathrm{min}$. The needle was left in place for an additional $5 \mathrm{~min}$ after the injection and then slowly withdrawn. Gelfoam was placed in the burr hole, the incision sutured closed, and the animals returned to their home cages for recovery.

Methamphetamine treatment. One day after GDNF or vehicle administration, the rats were injected subcutaneously with $5 \mathrm{mg} / \mathrm{kg}$ methamphetamine hydrochloride (Sigma, St. Louis, MO) in saline $(1 \mathrm{ml} / \mathrm{kg}$ ) or saline alone $(1 \mathrm{ml} / \mathrm{kg})$ four times in $1 \mathrm{~d}$ at $2 \mathrm{hr}$ intervals. The first injection of the series was given between 8:30 and 9:00 AM, and the temperature of the room was $21^{\circ} \mathrm{C}$. Approximately $30 \%$ of the animals died from the METH treatment. The GDNF administration did not improve survival rate.

In vivo electrochemistry. One week after treatment with METH or saline, the animals were anesthetized with urethane $(1.25-1.5 \mathrm{gm} / \mathrm{kg}$, i.p.) and placed into a stereotaxic frame. Body temperature was maintained at $37^{\circ} \mathrm{C}$ by a heating pad coupled to a rectal thermometer. The scalp was reflected, and the skull and dura overlying the frontal cortices were removed bilaterally. A small hole was drilled in the skull over the posterior cortex for placement of $\mathrm{Ag} / \mathrm{AgCl}$ reference electrodes. The reference electrodes were secured in place with dental acrylic.

Electrode/micropipette assemblies were constructed by attaching single-barrel micropipettes to each electrode (Friedemann and Gerhardt, 1992). The tips of the micropipettes had outer diameters of $10-20 \mu \mathrm{m}$, and they were positioned $280-300 \mu \mathrm{m}$ from the tips of the electrodes. The micropipettes were filled with a solution containing $70 \mathrm{~mm} \mathrm{KCl}, 79$ $\mathrm{mM} \mathrm{NaCl}$, and $2.5 \mathrm{mM} \mathrm{CaCl}_{2}, \mathrm{pH}$ 7.4. The recording electrodes each contained a single carbon fiber sealed in a glass capillary (fiber diameter, $33 \mu \mathrm{m}$; exposed length, $90-150 \mu \mathrm{m}$ ). Before use, all electrodes were coated with Nafion (6-9 times, with drying at $200^{\circ} \mathrm{C}$ between coats) to increase selectivity of the electrodes for DA over ascorbic acid (Gerhardt et al., 1984). They were then calibrated in vitro at room temperature in 0.1 M PBS, pH 7.4, containing $250 \mu \mathrm{M}$ ascorbic acid. The response of all electrodes used was linear when calibrated with DA up to $20 \mu \mathrm{M}$ in concentration (correlation coefficients ranged from 0.998 to 1.000). The electrodes had a selectivity for DA over ascorbic acid of at least 600 to 1 and had high sensitivity for DA (15-94 nM, with a signal-to-noise ratio of 3.0).

High-speed chronoamperometric electrochemical measurements were made continuously at $5 \mathrm{~Hz}$ and averaged to $1 \mathrm{~Hz}$ using an IVEC-10 system (Medical Systems, Greenvale, NY). The applied oxidation potential was $+0.55 \mathrm{~V}$ for $100 \mathrm{msec}$ (vs the $\mathrm{Ag} / \mathrm{AgCl}$ reference electrodes), and the resting potential was $0.0 \mathrm{~V}$ for $100 \mathrm{msec}$. The oxidation and reduction currents were integrated digitally during the last $80 \mathrm{msec}$ of each 100 msec pulse. Electrode assemblies were initially positioned in the dorsal striatum (1.2 $\mathrm{mm}$ anterior to bregma, $2.2 \mathrm{~mm}$ lateral from midline, 3.5 $\mathrm{mm}$ below the surface of the brain). The baseline electrochemical signal was allowed to stabilize (5-10 min), and then $250-300 \mathrm{nl}$ of potassium solution was applied by pressure ejection (Picospritzer II, General Valve, Fairfield, NJ) to evoke the release of DA. The volume of fluid injected was monitored by determining the amount of fluid displaced from the micropipette using a dissection microscope fitted with a reticule eyepiece and was based on previous calculations that $\sim 250 \mathrm{nl}$ of solution is in a 1 mm segment of the micropipette (Friedemann and Gerhardt, 1992). The volume applied was chosen because it produces a maximal overflow of DA from saline- and METH-treated animals (Cass, 1997). After the signal had returned to baseline, the electrode/micropipette assembly was lowered by $0.5 \mathrm{~mm}$. The new baseline was allowed to stabilize, and then the potassium solution was applied again. The potassium applications were repeated at $0.5 \mathrm{~mm}$ steps to map the striatum and nucleus accum-
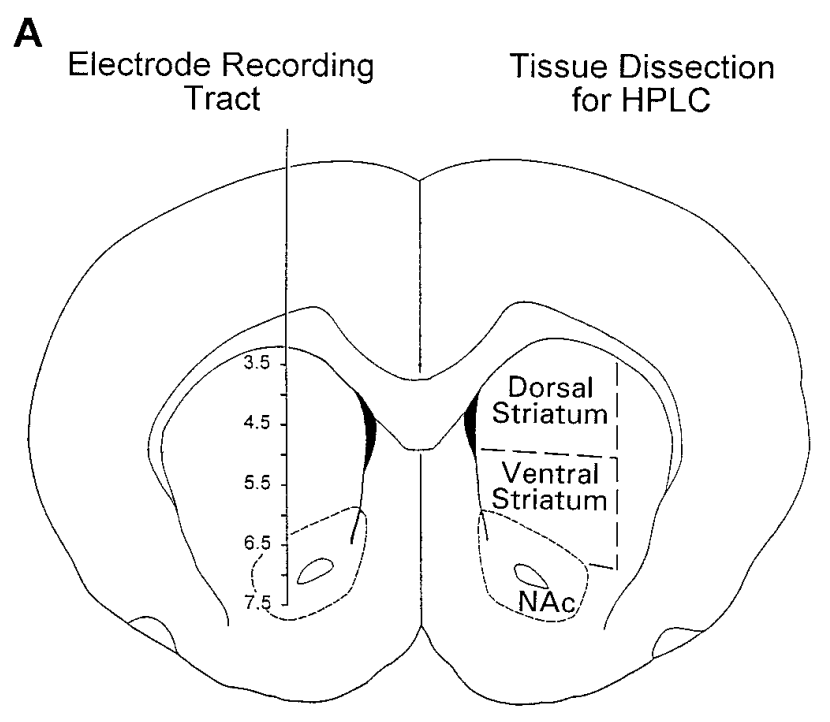

B

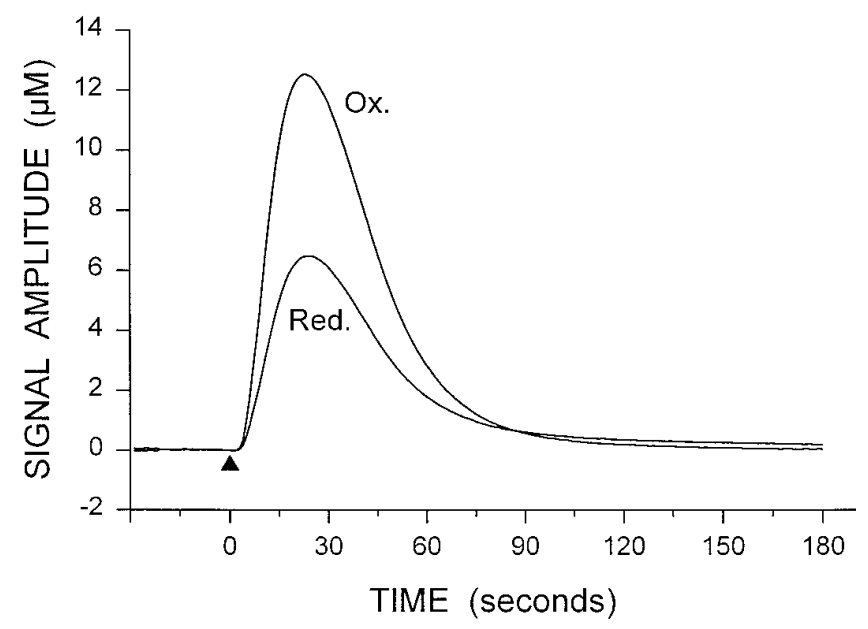

Figure 1. A, Illustration of the position of the recording electrode track for the in vivo electrochemistry experiments and the dissection of the striatum and nucleus accumbens (NAc) for HPLC analysis of monoamines. This coronal section is $\sim 1.2 \mathrm{~mm}$ rostral to bregma (Paxinos and Watson, 1986). $B$, Representative signal showing the potassium-evoked overflow of DA in the striatum of a control rat. Potassium $(300 \mathrm{nl}, 70 \mathrm{~mm}$ $\mathrm{K}^{+}$) was applied at the arrowhead. The oxidation $(O x$.$) and reduction$ (Red.) current responses (reduction/oxidation current ratio $=0.52$ ) indicate that the predominate electroactive species detected is DA.

bens. A single recording pass was made in both the right and left hemispheres of each animal. The order of the passes was alternated among animals.

Tissue collection and HPLC analysis. At the end of the experiments, the animals were killed by decapitation while still anesthetized with urethane. Animals used for tissue content studies that were not used for in vivo electrochemistry experiments were anesthetized with $\mathrm{CO}_{2}$ before decapitation. The brains were removed rapidly and chilled in ice-cold saline. A coronal slice of brain, $\sim 2 \mathrm{~mm}$ thick and containing the striatum and nucleus accumbens, was made with the aid of a chilled brain mold (Rodent Brain Matrix, ASI Instruments, Warren, MI). The location of the recording electrodes was confirmed by noting blood left in the recording track. The striatum and accumbens were dissected from each half of the slice as a single piece. The nucleus accumbens was cut away from the striatum, and the striatum separated into dorsal and ventral portions with a horizontal cut (Fig. 1A). The tissue pieces were placed in preweighed vials, weighed, and frozen on dry ice. Samples were stored at $-80^{\circ} \mathrm{C}$ until assayed by HPLC.

For determining monoamine content, the samples were sonicated in 
$300 \mu 1$ of cold $0.1 \mathrm{M}$ perchloric acid containing dihydroxybenzylamine as an internal standard. The samples were centrifuged for $5 \mathrm{~min}$ at $15,000 \times$ $g$ and the supernatant transferred to $0.22 \mu \mathrm{m}$ micropure separators (Amicon, Beverly, MA) and spun at $15,000 \times g$ for $1 \mathrm{~min}$. The filtrate was diluted with HPLC mobile phase and $50 \mu \mathrm{l}$ injected onto the HPLC column.

Levels of DA and 5-HT were determined by the procedure of Hall et al. (1989). The HPLC system consisted of a Beckman model 118 pump, a Beckman model 507 autoinjector, and an ESA model 5200A Coulochem II electrochemical detector with a model 5011 dual-detector analytical cell (detector 1 set at $+350 \mathrm{mV}$ and detector 2 set at $-250 \mathrm{mV}$ ). A Keystone Hypersil ODS $3 \mu \mathrm{m}$ particle $(4.6 \times 100 \mathrm{~mm}) \mathrm{C} 18$ column (Keystone Scientific, Bellefonte, PA) was used for separations. Flow rate was $1.6 \mathrm{ml} / \mathrm{min}$, and the mobile phase was a $\mathrm{pH} 4.1,0.17 \mathrm{M}$ citrate-acetate buffer (containing $50 \mathrm{mg} / \mathrm{l}$ EDTA, $130-150 \mathrm{mg} / \mathrm{l}$ octanesulfonic acid, and 7-12\% methanol). Chromatograms were recorded from both detectors using two dual-channel strip chart recorders. Retention times of standards were used to identify peaks, and peak heights were used to calculate recovery of internal standard as well as amounts of DA and 5-HT.

Data analysis. The electrodes used in this study, although relatively insensitive to ascorbic acid because of the Nafion coating, can still detect 5 -HT if the levels are high enough. To confirm that the responses detected were attributable primarily to DA, both the reduction and oxidation currents were recorded and the ratio of the reduction current to oxidation current calculated for each $\mathrm{K}^{+}$-induced response. The electrodes used in this study exhibit reduction/oxidation current ratios $\geq 0.4$ for DA and ratios of 0.0 to 0.2 for 5-HT (Luthman et al., 1993; Cass, 1997). Ascorbic acid, if detected, is not reduced at the potentials used and, therefore, gives a reduction/oxidation current ratio of 0.0 . All of the responses included in the results had reduction/oxidation ratios of at least 0.4 , indicating that DA was the predominant compound detected by the electrodes after potassium application. For statistical analyses, signal amplitude from the in vivo electrochemistry experiments and tissue monoamine concentration (expressed as $\mu \mathrm{g} / \mathrm{gm}$ wet weight of tissue) were analyzed using two-factor ANOVA followed by Newman-Keuls post hoc comparisons, or by paired $t$ tests.

\section{RESULTS}

\section{Potassium-evoked overflow of DA}

Locally applied potassium produced signals with reduction/oxidation current ratios characteristic for DA at all recording depths in the striatum and nucleus accumbens. A representative response, recorded from the ventral striatum at a depth of $6 \mathrm{~mm}$ below the surface of the cortex (see Fig. $1 A$ ), from a saline-treated control rat is shown in Figure $1 B$. Based on observations of the placement of the electrode tracts in the present study and on previous experience with recording from the striatum and nucleus accumbens (Cass et al. 1992, 1993; Cass and Gerhardt 1994, 1995), recordings at a depth of $3.5-6.0 \mathrm{~mm}$ below the surface of the cortex are contained within the striatum (Fig. $1 A$ ). Recordings at a depth of $6.5 \mathrm{~mm}$ are approximately at the junction of the striatum and nucleus accumbens, whereas recordings at depths of 7.0 and $7.5 \mathrm{~mm}$ are within the core of the nucleus accumbens.

In vivo electrochemistry experiments were carried out on animals that received the $10 \mu \mathrm{g}$ dose of GDNF. In the GDNF- and METH-treated animals, the amplitudes of the potassium-evoked signals were significantly higher on the right, GDNF-injected, side of the dorsal striatum in the region of the trophic factor administration (Figs. 2 and $3 A$ ). Signal amplitudes from the left side of the brain were consistently lower in amplitude and of similar amplitude at all recording depths (Fig. $3 A$ ). In the control animals receiving GDNF and saline, there was no difference in signal amplitude between the right and left sides of the brain at any specific depth, although there was a decline in amplitude at the ventral striatal recording sites that continued into the nucleus accumbens (Fig. 3B), as described previously (Cass, 1997). There was an abrupt drop in signal amplitude in the GDNF- and METH-treated animals from the $-5.5 \mathrm{~mm}$ to the $-6.0 \mathrm{~mm}$

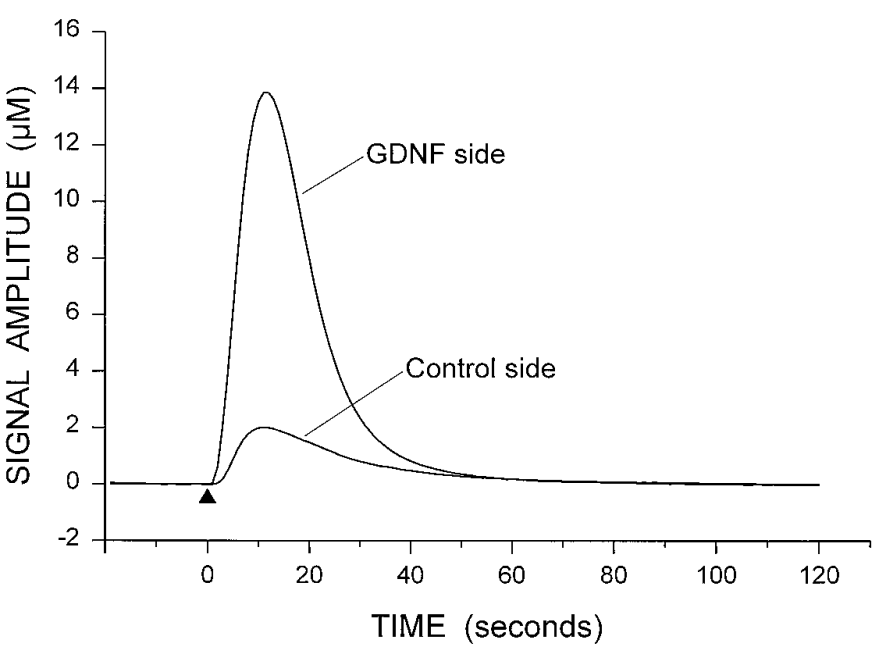

Figure 2. Representative signals for the potassium-evoked overflow of DA from the right side (GDNF side) and left side (Control side) of the dorsal striatum of a GDNF- and METH-treated animal. Potassium solution $(250 \mathrm{nl})$ was applied at the arrowhead in each case. For clarity, only the oxidation signals are shown.

recording sites; however, the signal amplitudes from the right side of the GDNF- and METH-treated animals were not significantly different from those recorded from the GDNF- and saline-treated group (mixed two-factor ANOVA: treatment $F=0.28, p=0.609$; depth $F=6.82, p<0.001$; interaction $F=1.304, p=0.257$ ). Amplitudes recorded from the left hemispheres of the GDNF animals were significantly different between the METH- and saline-treated groups (Fig. 3A,B) (treatment $F=11.09, p=$ 0.010 ; depth $F=6.92, p<0.001$; interaction $F=4.08, p<0.001$ ).

In contrast to the effects of GDNF, injection of vehicle solution into the right striatum $1 \mathrm{~d}$ before METH administration had no effect on potassium-evoked DA signal amplitude recorded 1 week later (Fig. 3C). Similarly, vehicle injection did not affect signal amplitude at any depth in the saline-treated animals (Fig. 3D).

\section{Tissue monoamine levels}

In the GDNF treated animals, the METH treatment significantly reduced DA levels in the left striatum (Table 1). The effect was greatest in the ventral striatum; a $74 \%$ decrease compared with the left side of the saline-treated animals. In the dorsal striatum, the decrease was $33 \%$. The GDNF injections significantly attenuated the DA-depleting effects of METH in the striatum. Compared with the right side of the saline-treated animals, DA depletions on the right side of the METH group were 31 and 5\% for the ventral and dorsal striatum, respectively. The $31 \%$ decrease in the ventral striatum was not significantly different from either side of the saline-treated group (ANOVA). GDNF administration had no effect on DA levels on the injected side of the brain, compared with the contralateral side, in the saline-treated group. In the nucleus accumbens, the GDNF had no effect on DA levels in the saline-treated animals. In the METH-treated animals, DA levels were not significantly reduced in the left nucleus accumbens in the overall ANOVA; however, there was a significant difference between the left and right sides of the METH group when examined by a paired $t$ test.

The administration of vehicle solution $24 \mathrm{hr}$ before METH had no effect on the ability of METH to reduce striatal levels of DA (Table 1). One week after METH treatment, DA levels on both sides of the brain were reduced by $34-39 \%$ in the dorsal striatum 

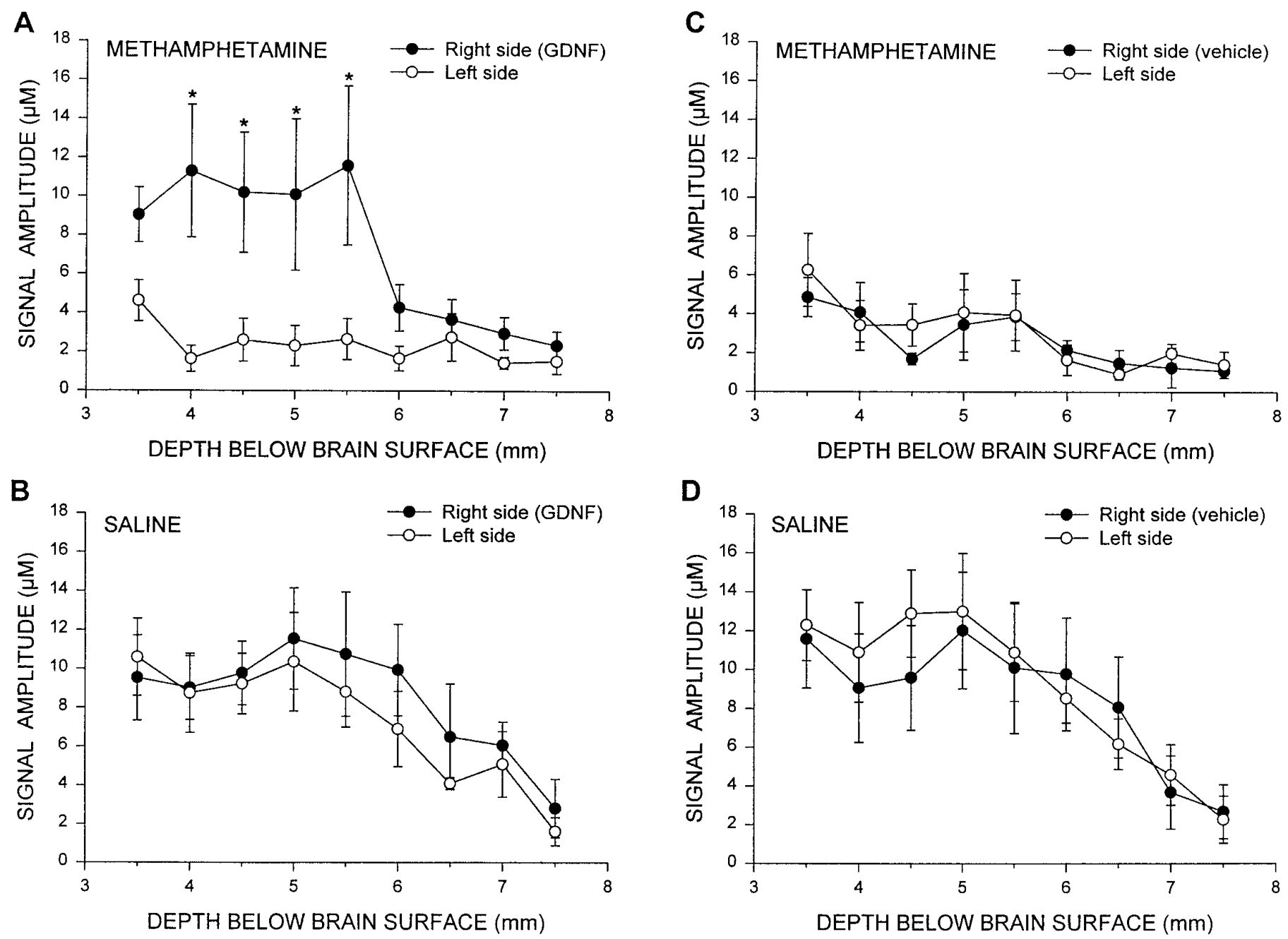

Figure 3. Summary of potassium-evoked DA signal amplitude throughout the striatum and nucleus accumbens of GDNF-treated animals administered METH $(A)$ or saline $(B)$ and vehicle-treated animals administered METH $(C)$ or saline $(D)$. GDNF or vehicle was injected into the right striatum 24 hr before METH or saline treatment. In vivo electrochemical recordings were made 1 week after METH or saline administration. The data shown are mean \pm SEM values for six animals per group for the GDNF groups $(A, B)$ and five animals per group for the saline groups $(C, D)$. The data were analyzed using two-factor ANOVA with side of brain and depth of recording as within factors. $F$ scores for the GDNF and METH group $(A)$ : $\operatorname{side} F=12.33, p=$ 0.025 ; depth $F=3.32, p=0.007$; interaction $F=3.32, p=0.007$. $F$ scores for the GDNF and saline group $(B)$ : $\operatorname{side} F=0.74, p=0.439$; depth $F=11.46$, $p<0.001$; interaction $F=1.47, p=0.206$. $F$ scores for the vehicle and METH group $(C)$ : $\operatorname{side} F=0.45, p=0.540$; depth $F=4.20, p=0.002$; interaction $F=0.74, p=0.658$. $F$ scores for the vehicle and saline group $(D)$ : side $F=0.36, p=0.579$; depth $F=5.05, p<0.001$; interaction $F=0.82, p=0.591$. ${ }^{*} p<0.05$ versus left side at same depth (Newman-Keuls post hoc comparisons).

and $60-62 \%$ in the ventral striatum compared with saline-treated controls. In the nucleus accumbens, DA levels were decreased by $26-31 \%$, but this decrease did not reach statistical significance.

5-HT levels were also decreased by the METH treatment. In the dorsal striatum, the decrease ranged from 42 to $61 \%$, and GDNF administration had no significant effect on this reduction (Table 2). In the ventral striatum, the METH-induced decreases in 5-HT ranged from 44 to $62 \%$, and GDNF administration did have a significant effect. 5-HT levels in the right ventral striatum were decreased by only $24 \%$ in the GDNF- and METH-treated group. In the nucleus accumbens, 5-HT levels were decreased by up to $22 \%$ in the METH-treated groups. However, this decrease was not significant, and GDNF administration had no significant effect on these levels.

The dose of GDNF examined in the in vivo electrochemistry experiments, $10 \mu \mathrm{g}$, was chosen because it has been shown to partially protect DA neurons from 6-OHDA and MPTP toxicity
(Kearns and Gash, 1995; Tomac et al., 1995). However, in the present study, $10 \mu \mathrm{g}$ of GDNF afforded nearly complete protection to DA neurons against the effects of neurotoxic doses of METH. Because of this, two lower doses of GDNF, 1.0 and 0.1 $\mu \mathrm{g}$, were examined along with the $10 \mu \mathrm{g}$ dose again, to determine more comprehensively the ability of GDNF to protect against METH-induced reductions in striatal DA and 5-HT content.

In this second series of experiments, DA levels on the left side of the brain of the METH-treated animals were reduced by $40-43 \%$ and $46-56 \%$ in the dorsal and ventral striatum, respectively (Fig. 4). DA levels on the right, GDNF-injected, side of the dorsal and ventral striatum were not significantly different from the control animals in the 1.0 and $10 \mu \mathrm{g}$ groups. In the $0.1 \mu \mathrm{g}$ group, DA levels were significantly greater on the right side of the brain compared with the left side, but they were also lower than in the control animals. In the nucleus accumbens, DA levels on the left side of the METH-treated animals were significantly reduced 
Table 1. DA concentrations from animals treated with GDNF or vehicle 1 d before METH or saline administration

\begin{tabular}{|c|c|c|c|c|}
\hline Region & $\begin{array}{l}\text { GDNF + } \\
\text { METH }\end{array}$ & $\begin{array}{l}\text { GDNF + } \\
\text { saline }\end{array}$ & $\begin{array}{l}\text { Vehicle + } \\
\text { METH }\end{array}$ & $\begin{array}{l}\text { Vehicle + } \\
\text { saline }\end{array}$ \\
\hline \multicolumn{5}{|c|}{ Dorsal striatum } \\
\hline Right & $11.7 \pm 1.2$ & $12.3 \pm 1.3$ & $7.8 \pm 1.3^{\#}$ & $11.9 \pm 1.3$ \\
\hline Left & $7.8 \pm 1.1^{*}$ & $11.7 \pm 1.6$ & $7.8 \pm 0.8^{\#}$ & $12.8 \pm 1.1$ \\
\hline \multicolumn{5}{|c|}{ Ventral striatum } \\
\hline Right & $6.2 \pm 0.7$ & $9.1 \pm 0.9$ & $3.9 \pm 0.7^{\#}$ & $9.6 \pm 0.9$ \\
\hline Left & $2.2 \pm 0.5^{*}$ & $8.7 \pm 1.3$ & $3.7 \pm 0.4^{\#}$ & $9.6 \pm 1.0$ \\
\hline \multicolumn{5}{|c|}{ Nucleus accumbens } \\
\hline Right & $5.4 \pm 0.8$ & $5.6 \pm 0.9$ & $3.6 \pm 0.4$ & $5.2 \pm 0.7$ \\
\hline Left & $3.6 \pm 0.3^{+}$ & $5.0 \pm 0.6$ & $3.9 \pm 0.6$ & $5.3 \pm 0.8$ \\
\hline
\end{tabular}

Levels are expressed as $\mu \mathrm{g} / \mathrm{g}$ wet weight of tissue. Values are mean $\pm \mathrm{SEM} ; n=8$ or 9 for all groups.

${ }^{*} p<0.05$ compared with right side of brain and both sides of GDNF + saline group (two-factor ANOVA with side of brain as a within factor, followed by NewmanKeuls post hoc comparisons);

${ }^{\#} p<0.05$ compared with both sides of vehicle + saline group.

${ }^{+} p<0.05$ compared with right side of GDNF + METH group (paired $t$ test).

Table 2. 5-HT concentrations from animals treated with GDNF or vehicle $1 \mathrm{~d}$ before METH or saline administration

\begin{tabular}{lllll} 
Region & $\begin{array}{l}\text { GDNF }+ \\
\text { METH }\end{array}$ & $\begin{array}{l}\text { GDNF }+ \\
\text { saline }\end{array}$ & $\begin{array}{l}\text { Vehicle }+ \\
\text { METH }\end{array}$ & $\begin{array}{l}\text { Vehicle }+ \\
\text { saline }\end{array}$ \\
\hline $\begin{array}{l}\text { Dorsal striatum } \\
\text { Right }\end{array}$ & $0.15 \pm 0.02^{*}$ & $0.28 \pm 0.04$ & $0.16 \pm 0.02^{*}$ & $0.28 \pm 0.03$ \\
$\quad \begin{array}{l}\text { Left } \\
\text { Ventral striatum }\end{array}$ & $0.11 \pm 0.02^{*}$ & $0.28 \pm 0.05$ & $0.15 \pm 0.02^{*}$ & $0.27 \pm 0.02$ \\
$\quad$ & & & \\
$\quad \begin{array}{l}\text { Right } \\
\text { Left }\end{array}$ & $0.31 \pm 0.06$ & $0.41 \pm 0.07$ & $0.28 \pm 0.05^{*}$ & $0.50 \pm 0.05$ \\
Nucleus accumbens & $0.18 \pm 0.03^{*}$ & $0.47 \pm 0.11$ & $0.26 \pm 0.03^{*}$ & $0.47 \pm 0.03$ \\
$\quad \begin{array}{llll}\text { Right } \\
\text { Left }\end{array}$ & $0.41 \pm 0.07$ & $0.43 \pm 0.08$ & $0.39 \pm 0.04$ & $0.52 \pm 0.06$ \\
& $0.39 \pm 0.08$ & $0.51 \pm 0.08$ & $0.45 \pm 0.04$ & $0.58 \pm 0.03$
\end{tabular}

Levels are expressed as $\mu \mathrm{g} / \mathrm{g}$ wet weight of tissue. Values are mean $\pm \mathrm{SEM} ; n=8$ or 9 for all groups.

$* p<0.05$ compared with respective saline control group (two-factor ANOVA with side of brain as a within factor; followed by Newman-Keuls post hoc comparisons).

by 25 and $32 \%$ in the 0.1 and $10 \mu$ g groups, respectively (Fig. $4 C$ ). The decrease in DA levels on the left side of the $1.0 \mu \mathrm{g}$ group (23\%) was not significant at the $p<0.05$ level. Nucleus accumbens DA levels on the GDNF-injected side were greater than on the contralateral side and not significantly lower than control values in the 1.0 and $10 \mu \mathrm{g}$ groups. However, in the $0.1 \mu \mathrm{g}$ group, the GDNF had no significant effect.

5-HT levels were decreased $43-49 \%$ in the dorsal striatum, $44-53 \%$ in the ventral striatum, and $30-38 \%$ in the nucleus accumbens of the METH-treated rats (Fig. 5). However, GDNF had no significant effect on 5-HT levels in any region examined at any dose (Fig. 5).

\section{DISCUSSION}

METH is a potent psychomotor stimulant that can also act as a dopaminergic and serotonergic neurotoxin. In the present study, $10 \mu \mathrm{g}$ of GDNF, administered directly into the striatum $24 \mathrm{hr}$ before METH treatment, afforded nearly complete protection against the dopaminergic toxicity of METH. Potassium-evoked release was maintained at $100 \%$ of control values, and DA levels in the GDNF-treated side in the striatum and nucleus accumbens were not significantly different from levels in the saline-treated
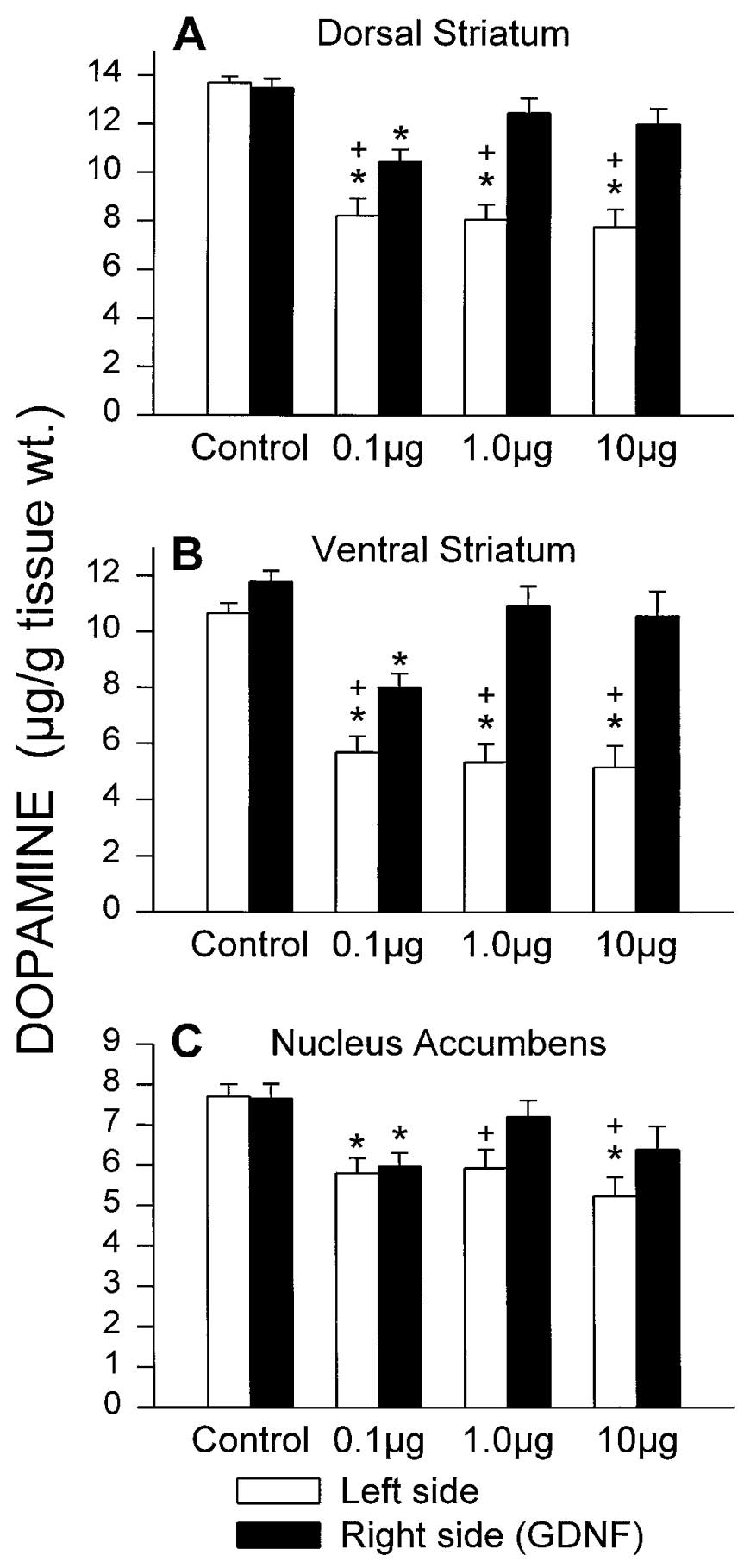

Figure 4. DA levels in the striatum and nucleus accumbens of GDNFtreated animals administered METH $24 \mathrm{hr}$ after the GDNF. Doses of GDNF $(0.1,1.0$, and $10 \mu \mathrm{g})$ are shown on the horizontal axis. Control animals were given intrastriatal injections of vehicle and administered saline $24 \mathrm{hr}$ later. Tissue was taken 1 week after METH or saline treatment and divided into dorsal striatum $(A)$, ventral striatum $(B)$, and nucleus accumbens $(C)$, as indicated in Figure $1 A$. The data shown are mean \pm SEM values for 9 or 10 animals per group. The data were analyzed using two-factor ANOVA with side of brain as a within factor. $F$ scores for dorsal striatum $(A)$ : $\operatorname{dose} F=12.0, p<0.001$; side $F=109.2$, $p<0.001$; interaction $F=17.6, p<0.01$. $F$ scores for ventral striatum $(B)$ : dose $F=8.67, p<0.001$; side $F=202.8, p<0.001$; interaction $F=13.6$, $p<0.001 . F$ scores for nucleus accumbens $(C)$ : $\operatorname{dose} F=5.10, p=0.005$; side $F=13.7, p<0.001$; interaction $F=3.86, p=0.02$. ${ }^{*} p<0.05$ versus same side of control group; ${ }^{+} p<0.05$ versus right side of brain at same dose (Newman-Keuls post hoc comparisons). 


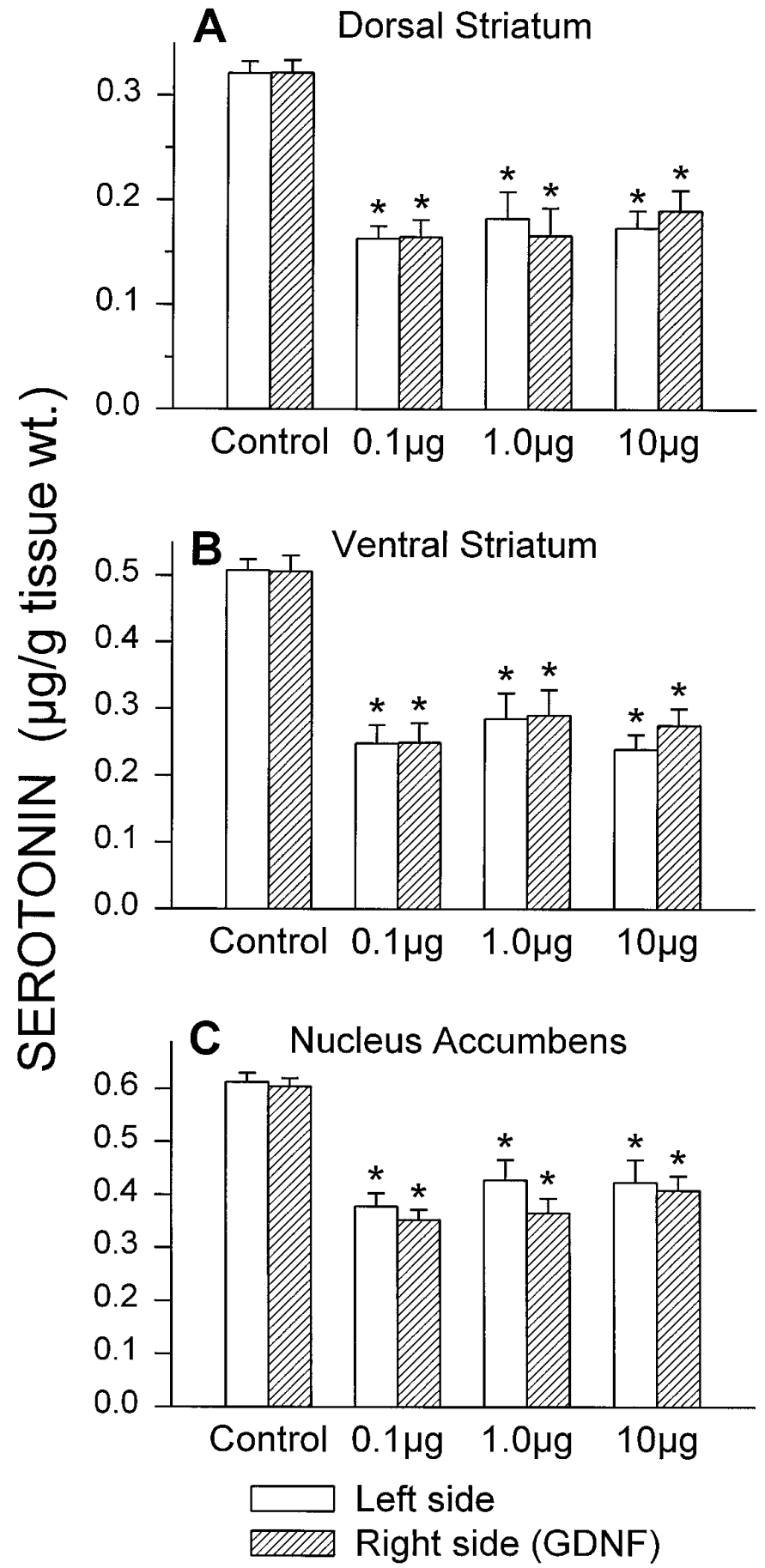

Figure 5. 5-HT levels in the striatum and nucleus accumbens of GDNFtreated animals administered METH $24 \mathrm{hr}$ after the GDNF. Doses of GDNF $(0.1,1.0$, and $10 \mu \mathrm{g})$ are shown on the horizontal axis. Control animals were given intrastriatal injections of vehicle and administered saline $24 \mathrm{hr}$ later. Tissue was taken 1 week after METH or saline treatment and divided into dorsal striatum $(A)$, ventral striatum $(B)$, and nucleus accumbens $(C)$, as indicated in Figure $1 A$. The data shown are mean \pm SEM values for 9 or 10 animals per group. The data were analyzed using two-factor ANOVA with side of brain as a within factor. $F$ scores for dorsal striatum $(A)$ : $\operatorname{dose} F=16.5, p<0.001$; $\operatorname{side} F=0.08, p=$ 0.78 ; interaction $F=2.18, p=0.11$. $F$ scores for ventral striatum $(B)$ : dose $F=16.7, p<0.001$; $\operatorname{side} F=0.78, p=0.38$; interaction $F=0.94, p=0.43$. $F$ scores for nucleus accumbens $(C)$ : $\operatorname{dose} F=20.4, p<0.001$; side $F=$ $3.14, p=0.09$; interaction $F=0.59, p=0.63$. ${ }^{*} p<0.05$ versus same side of control group (Newman-Keuls post hoc comparisons). controls. This is in contrast to protection against MPTP and 6-OHDA-induced damage, in which GDNF typically affords only partial protection. In mice given intrastriatal or intranigral GDNF $24 \mathrm{hr}$ before systemic MPTP, striatal and nigral DA levels are only partially protected (Tomac et al., 1995). When administered into the nigral region $24 \mathrm{hr}$ before 6-OHDA (Kearns and Gash, 1995), or $7 \mathrm{~d}$ after 6-OHDA (Sauer et al., 1995), GDNF improved the survival of nigral DA neurons. However, the number of surviving neurons was still below control numbers. Similarly, striatal DA levels were partially protected from depletion when GDNF was administered dorsal to the substantia nigra or into the lateral ventricle immediately before 6-OHDA (Opacka-Juffry et al., 1995). In contrast, supranigral administration of GDNF every other day for 4 weeks, starting on the day of an intrastriatal 6-OHDA lesion, completely prevented loss of cells in the substantia nigra (Sauer et al., 1995). In addition, when GDNF was injected into the striatum 1 and $3 \mathrm{~d}$ before and 1 and $4 \mathrm{~d}$ after intrastriatal administration of 6-OHDA, the density of tyrosine hydroxylase-positive fibers in the striatum was partially preserved, and the number of tyrosine hydroxylase-positive neurons in the substantia nigra was almost completely preserved (Shults et al., 1996). The more extended GDNF treatment schedules in these latter two studies appear to provide a greater degree of protection against the effects of 6-OHDA.

The dose-response experiments in the present study indicate that $1.0 \mu \mathrm{g}$ of GDNF is as effective as $10 \mu \mathrm{g}$ in protecting against the DA-depleting effects of METH. In a similar manner, Shults et al. (1996) found that with repeated intrastriatal administration of GDNF, $1.0 \mu \mathrm{g}$ was as effective as $10 \mu \mathrm{g}$ in preventing the effects of 6-OHDA on DA neurons. These results suggest that $1.0 \mu \mathrm{g}$ of GDNF, when administered intrastriatally, is a maximally effective dose that likely leads to maximal activation of GDNF receptors. Taken together with the studies discussed above, these results indicate that the site of injection, the time course for delivery, and the dose of GDNF are all important for determining the extent of protection against various dopaminergic toxins.

There are a couple of possibilities to explain why a single injection of GDNF provided such complete protection against the DA-depleting effects of METH in the present study. One is the fact that the GDNF was administered directly into the striatum. This was done because the primary neurotoxic effects of METH on DA neurons are at the terminal regions; there is little or no loss of DA or cell bodies in the substantia nigra (Ricaurte et al., 1982; Seiden and Ricaurte, 1987; Cass, 1997). Thus, injecting GDNF directly into the region of the brain susceptible to METH toxicity may have increased the protective properties of GDNF. A second possible reason for the greater extent of protection is that the magnitude of the DA depletion is less severe after METH administration ( $\sim 60 \%$ or less); whereas with MPTP and 6-OHDA, the magnitude of depletion is often $\geq 90 \%$.

The protection of potassium-evoked overflow of DA in the striatum by GDNF is similar to recent results concerning 6-OHDA lesions. Using microdialysis, Opacka-Juffry et al. (1995) found that GDNF prevented 6-OHDA-induced decreases in basal extracellular DA levels in the striatum and that potassiumstimulated DA overflow was four times greater in GDNF-treated 6-OHDA lesioned striatum compared with control 6-OHDA lesioned striatum. In the present study, GDNF administration prevented the loss in potassium-evoked overflow of DA normally observed after METH treatment (Cass, 1997). Statistically, the protection was $100 \%$. However, there was more variability in the data from the GDNF- and METH-treated animals compared with 
the saline-treated controls (Fig. 3). This variability was not always attributable to differences among animals but often to large variations from site to site within animals. This made it appear that the protection afforded by GDNF was heterogeneous rather than uniform in nature.

The experiments in which animals were treated with saline after GDNF administration were designed to control for the possibility that GDNF may upregulate DA systems in the normal brain and appear to offset the DA-depleting effects of METH. However, this does not appear to be the case. In the saline-treated animals, GDNF did not augment either potassium-evoked overflow of DA or tissue content of DA in the striatum. Similarly, other investigators have reported that striatal DA levels are not increased at 1 or 3 weeks after intracerebral injection of GDNF in adult rats (Hudson et al., 1995; Beck et al., 1996). These data indicate that the GDNF treatment does not in itself increase striatal DA overflow or content 1 week later. Thus, the present results are attributable to GDNF protecting against the DA-depleting actions of METH and are not attributable to a unilateral upregulation of the nigrostriatal system on the injected side that simply offsets the effects of METH.

Along with its effects on DA terminals, METH can also affect 5-HT systems (Gibb et al., 1994). The decreases in 5-HT levels in the striatum of the METH-treated animals are in agreement with this. However, GDNF did not significantly protect against METHinduced reductions of 5-HT in the dorsal striatum or nucleus accumbens. In the ventral striatum, 5-HT levels were only partially protected in the first series of experiments and not protected at all in the dose-response experiments. Other investigators have reported that the effects of GDNF on 5-HT systems are less extensive compared with DA systems (Lin et al., 1993; Hoffer et al., 1994; Gash et al., 1995; Hudson et al., 1995; Tomac et al., 1995), so the present results are not without precedents. However, the relative lack of effects on 5-HT systems, whereas DA systems are extensively protected, indicates that the protective effects of GDNF are directed toward DA neurons and are not a generalized phenomenon.

Although the mechanisms for GDNF-induced protection against dopaminergic toxins are not presently known, there are indications that the neuroprotective effects of other neurotrophic factors may include activation or upregulation of antioxidant enzymes (Spina et al., 1992; Mattson et al., 1993). In addition, injection of the protein synthesis inhibitor cycloheximide into the nigra $1 \mathrm{hr}$ before GDNF prevents the neuroprotective effects of GDNF against 6-OHDA-induced reductions in nigral DA cell number (C.M. Kearns, personal communication). This suggests that protein synthesis is necessary for the neuroprotective effects of GDNF. Thus, for instance, if excessive generation of free radicals is necessary for the neurotoxic effects of METH on DA and 5-HT systems (Cadet et al., 1994; Giovanni et al., 1995; Hirata et al., 1995), and if GDNF is protecting DA neurons by upregulating enzymatic systems that scavenge these radicals, then the upregulated systems appear to be localized primarily to DA neurons. One possible explanation for this preferential effect of GDNF on DA neurons over 5-HT neurons concerns the recently identified receptor for GDNF (Durbec et al., 1996; Jing et al., 1996; Treanor et al., 1996; Trupp et al., 1996). The receptor system is a multicomponent complex, the components of which are expressed by midbrain DA neurons (Treanor et al., 1996; Trupp et al., 1996). If one of these necessary components is not expressed in adult 5-HT neurons or is expressed in substantially lower amounts, this could explain the relative lack of effects of GDNF on these neurons.

METH neurotoxicity is also used as a model for Parkinson's disease (Walsh and Wagner, 1992; Zeevalk et al., 1994; Dawson et al., 1995). The loss of DA in the striatum is a hallmark of this progressive, debilitating disorder (Hornykiewicz, 1993). Behaviorally, animals treated with neurotoxic doses of METH display few changes in motor performance (Walsh and Wagner, 1992; Ricaurte et al., 1994). However, at least one of the changes they do show, increased footslips on a balance beam, is improved by systemically administered L-dopa (Walsh and Wagner, 1992). The lack of overt behavioral changes is not surprising considering that METH-induced depletion of striatal DA is $<80 \%$. Thus, although the lesion produced by METH is not as severe as with some other toxins, such as 6-OHDA and MPTP, the METH model may represent a good model for early, or preclinical, stages of Parkinson's disease. The neuroprotective ability of GDNF against METH-induced changes in striatal DA release and content provides additional evidence that this neurotrophic factor may have potential use for the treatment of Parkinson's disease or to help halt its progression.

In summary, the intrastriatal application of GDNF $1 \mathrm{~d}$ before METH treatment prevented METH-induced reductions in striatal DA release and content. In contrast, GDNF provided little, if any, protection against METH-induced depletions of 5-HT. These results provide the first evidence that GDNF is protective against the dopaminergic toxicity of METH and provide additional evidence that GDNF has potent neuroprotective properties in general against dopaminergic toxins.

\section{REFERENCES}

Axt KJ, Mamounas LA, Molliver ME (1994) Structural features of amphetamine neurotoxicity in the brain. In: Amphetamine and its analogs: psychopharmacology, toxicology, and abuse (Cho AK, Segal DS, eds), pp 315-367. San Diego: Academic.

Beck KD, Valverde J, Alexi T, Poulsen K, Moffat B, Vandlen RA, Rosenthal A, Hefti F (1995) Mesencephalic dopaminergic neurons protected by GDNF from axotomy-induced degeneration in the adult brain. Nature 373:339-341.

Beck KD, Irwin I, Valverde J, Brennan TJ, Langston JW, Hefti F (1996) GDNF induces a dystonia-like state in neonatal rats and stimulates dopamine and serotonin synthesis. Neuron 16:665-673.

Bittner SE, Wagner GC, Aigner TG, Seiden LS (1981) Effects of highdose treatment of methamphetamine on caudate dopamine and anorexia in rats. Pharmacol Biochem Behav 14:481-486.

Bowenkamp KE, Hoffman AF, Gerhardt GA, Henry MA, Biddle P, Hoffer BJ, Granholm A-CE (1995) Glial cell line-derived neurotrophic factor supports survival of injured midbrain dopaminergic neurons. J Comp Neurol 355:479-489.

Bowyer JF, Davies DL, Schmued L, Broening HW, Newport GD, Slikker WJr Holson RR (1994) Further studies of the role of hyperthermia in methamphetamine neurotoxicity. J Pharmacol Exp Ther 268:1571-1580.

Cadet JL, Sheng P, Ali S, Rothman R, Carlson E, Epstein C (1994) Attenuation of methamphetamine-induced neurotoxicity in copper/zinc superoxide dismutase transgenic mice. J Neurochem 62:380-383.

Cass WA (1997) Decreases in evoked overflow of dopamine in rat striatum following neurotoxic doses of methamphetamine. J Pharmacol Exp Ther, in press.

Cass WA, Gerhardt GA (1994) Direct in vivo evidence that D2 dopamine receptors can modulate dopamine uptake. Neurosci Lett 176:259-263.

Cass WA, Gerhardt GA (1995) In vivo assessment of dopamine uptake in rat medial prefrontal cortex: comparison with dorsal striatum and nucleus accumbens. J Neurochem 65:201-207.

Cass WA, Gerhardt GA, Mayfield RD, Curella P, Zahniser NR (1992) Differences in dopamine clearance and diffusion in rat striatum and nucleus accumbens following systemic cocaine administration. J Neurochem 59:259-266. 
Cass WA, Zahniser NR, Flach KA, Gerhardt GA (1993) Clearance of exogenous dopamine in rat dorsal striatum and nucleus accumbens: role of metabolism and effects of locally applied uptake inhibitors. J Neurochem 61:2269-2278.

Dawson Jr R, Beal MF, Bondy SC, DiMonte DA, Isom GE (1995) Excitotoxins, aging, and environmental neurotoxins: implications for understanding human neurodegenerative diseases. Toxicol Appl Pharmacol 134:1-17.

Durbec P, Marcos-Gutierrez CV, Kilkenny C, Grigoriou M, Wartiowaara K, Suvanto P, Smith D, Ponder B, Costantini F, Saarma M, Sariola H, Pachnis V (1996) GDNF signalling through the Ret receptor tyrosine kinase. Nature 381:789-793.

Finnegan KT, Ricaurte G, Seiden LS, Schuster CR (1982) Altered sensitivity to D-methylamphetamine, apomorphine, and haloperidol in rhesus monkeys depleted of caudate dopamine by repeated administration of D-methylamphetamine. Psychopharmacology 77:43-52.

Friedemann MN, Gerhardt GA (1992) Regional effects of aging on dopaminergic function in the Fischer-344 rat. Neurobiol Aging 13:325-332.

Garris PA, Wightman RM (1994) Different kinetics govern dopaminergic transmission in the amygdala, prefrontal cortex, and striatum: an in vivo voltammetric study. J Neurosci 14:442-450.

Gash DM, Zhang Z, Cass WA, Ovadia A, Simmerman L, Martin D, Russell D, Collins F, Hoffer BJ, Gerhardt GA (1995) Morphological and functional effects of intranigrally administered GDNF in normal rhesus monkeys. J Comp Neurol 363:345-358.

Gash DM, Zhang Z, Ovadia A, Cass WA, Yi A, Simmerman L, Russell D, Martin D, Lapchak PA, Collins F, Hoffer BJ, Gerhardt GA (1996) Functional recovery in GDNF-treated parkinsonian monkeys. Nature 380:252-255.

Gerhardt GA, Oke AF, Nagy G, Moghaddam B, Adams RN (1984) Nafion-coated electrodes with high selectivity for CNS electrochemistry. Brain Res 290:390-395.

Gibb JW, Hanson GR, Johnson M (1994) Neurochemical mechanisms of toxicity. In: Amphetamine and its analogs: psychopharmacology, toxicology, and abuse (Cho AK, Segal DS, eds), pp 269-295. San Diego: Academic.

Giovanni A, Liang LP, Hastings TG, Zigmond MJ (1995) Estimating hydroxy radical content in rat brain using systemic and intraventricular salicylate: impact of methamphetamine. J Neurochem 64:1819-1825.

Gratton A, Wise RA (1994) Drug- and behavior-associated changes in dopamine-related electrochemical signals during intravenous cocaine self-administration in rats. J Neurosci 14:4130-4146.

Hall ME, Hoffer BJ, Gerhardt GA (1989) Rapid and sensitive determination of catecholamines in small tissue samples by high performance liquid chromatography coupled with dual-electrode coulometric electrochemical detection. LC/GC 7:258-265.

Hirata H, Ladenheim B, Rothman RB, Epstein C, Cadet JL (1995) Methamphetamine-induced serotonin neurotoxicity is mediated by superoxide radicals. Brain Res 677:345-347.

Hoffer BJ, Hoffman A, Bowenkamp K, Huettl P, Hudson J, Martin D, Lin L-FH, Gerhardt GA (1994) Glial cell line-derived neurotrophic factor reverses toxin-induced injury to midbrain dopaminergic neurons in vivo. Neurosci Lett 182:107-111.

Hornykiewicz O (1993) Parkinson's disease and the adaptive capacity of the nigrostriatal dopamine system: possible neurochemical mechanisms. Adv Neurol 60:140-147.

Hou J-GG, Lin L-FH, Mytilineou C (1996) Glial cell line-derived neurotrophic factor exerts neurotrophic effects on dopaminergic neurons in vitro and promotes their survival and regrowth after damage by 1-methyl-4-phenylpyridinium. J Neurochem 66:74-82.

Hudson J, Granholm A-C, Gerhardt G, Henry MA, Hoffman A, Biddle P, Leela NS, Mackerlova L, Lile JD, Collins F, Hoffer BJ (1995) Glial cell line-derived neurotrophic factor augments midbrain dopaminergic circuits in vivo. Brain Res Bull 36:425-432.

Jing S, Wen D, Yu Y, Holst PL, Luo Y, Fang M, Tamir R, Antonio L, Hu Z, Cupples R, Louis J-C, Hu S, Altrock BW, Fox GM (1996) GDNFinduced activation of the Ret protein tyrosine kinase is mediated by GDNFR-alpha, a novel receptor for GDNF. Cell 85:1113-1124.

Kearns CM, Gash DM (1995) GDNF protects nigral dopamine neurons against 6-hydroxydopamine in vivo. Brain Res 672:104-111.

Lin L-FH, Doherty DH, Lile JD, Bektesh S, Collins F (1993) GDNF: a glial cell line-derived neurotrophic factor for midbrain dopaminergic neurons. Science 260:1130-1132.
Lorez H (1981) Fluorescence histochemistry indicates damage of striatal dopamine nerve terminals in rats after multiple doses of methamphetamine. Life Sci 28:911-916.

Luthman J, Friedemann M, Bickford P, Olson L, Hoffer BJ, Gerhardt GA (1993) In vivo electrochemical measurements and electrophysiological studies of rat striatum following neonatal 6-hydroxydopamine treatment. Neuroscience 52:677-687.

Martin D, Miller G, Fischer N, Dix D, Cullen T, Russell D (1996) Glial cell line-derived neurotrophic factor: the lateral cerebral ventricle as a site of administration for stimulation of the substantia nigra dopamine system in rats. Eur J Neurosci 8:1249-1255.

Mattson MP, Cheng B, Smith-Swintosky VL (1993) Neurotrophic factor mediated protection from excitotoxicity and disturbances in calcium and free radical metabolism. Semin Neurosci 5:295-307.

Opacka-Juffry J, Ashworth S, Hume SP, Martin D, Brooks DJ, Blunt SB (1995) GDNF protects against 6-OHDA nigrostriatal lesion: in vivo study with microdialysis and PET. NeuroReport 7:348-352.

Paxinos G, Watson C (1986) The rat brain in stereotaxic coordinates, 2nd ed. New York: Academic.

$\mathrm{Pu}$ C, Vorhees CV (1995) Protective effects of MK-801 on methamphetamine-induced depletion of dopaminergic and serotonergic terminals and striatal astrocytic response: an immunohistochemical study. Synapse 19:97-104.

Ricaurte GA, Guillery RW, Seiden LS, Schuster CR, Moore RY (1982) Dopamine nerve terminal degeneration produced by high doses of methylamphetamine in the rat brain. Brain Res 235:93-103.

Ricaurte GA, Sabol KE, Seiden LS (1994) Functional consequences of neurotoxic amphetamine exposure. In: Amphetamine and its analogs: psychopharmacology, toxicology, and abuse (Cho AK, Segal DS, eds), pp 297-313. San Diego: Academic.

Sauer H, Rosenblad C, Bjorklund A (1995) Glial cell line-derived neurotrophic factor but not transforming growth factor $\beta 3$ prevents delayed degeneration of nigral dopaminergic neurons following striatal 6-hydroxydopamine lesions. Proc Natl Acad Sci USA 92:8935-8939.

Seiden LS, Ricaurte GA (1987) Neurotoxicity of methamphetamine and related drugs. In: Psychopharmacology: the third generation of progress (Meltzer HY, ed), pp 359-366. New York: Raven.

Seiden LS, Fischman MW, Schuster CR (1975/76) Long-term methamphetamine induced changes in brain catecholamines in tolerant rhesus monkeys. Drug Alcohol Depend 1:215-219.

Shults CW, Kimber T, Martin D (1996) Intrastriatal injection of GDNF attenuates the effects of 6-hydroxydopamine. NeuroReport 7:627-631.

Spina MB, Squinto SP, Miller J, Lindsay RM, Hyman C (1992) Brainderived neurotrophic factor protects dopamine neurons against 6-hydroxydopamine and $N$-methyl-4-phenylpyridinium ion toxicity: involvement of the glutathione system. J Neurochem 59:99-106.

Suaud-Chagny MF, Dugast C, Chergui K, Msghina M, Ganon F (1995) Uptake of dopamine released by impulse flow in the rat mesolimbic and striatal systems in vivo. J Neurochem 65:2603-2611.

Tomac A, Lindqvist E, Lin L-FH, Ogren SO, Young D, Hoffer BJ, Olson $\mathrm{L}$ (1995) Protection and repair of the nigrostriatal dopaminergic system by GDNF in vivo. Nature 373:335-339.

Treanor JJS, Goodman L, de Sauvage F, Stone DM, Poulsen KT, Beck CD, Gray C, Armanini MP, Pollock RA, Hefti F, Phillips HS, Goddard A, Moore MW, Buj-Bello A, Davies AM, Asai N, Takahashi M, Vandlen R, Henderson CE, Rosenthal A (1996) Characterization of a multicomponent receptor for GDNF. Nature 382:80-83.

Trupp M, Arenas E, Fainzilber M, Nilsson A-S, Sieber B-A, Grigoriou M, Kilkenny C, Salazar-Grueso E, Pachnis V, Arumäe U, Sariola H, Saarma M, Ibáñez CF (1996) Functional receptor for GDNF encoded by the c-ret proto-oncogene. Nature 381:785-789.

Walsh SL, Wagner GC (1992) Motor impairments after methamphetamine-induced neurotoxicity in the rat. J Pharmacol Exp Ther 263:617-626.

Wood ER, Coury A, Blaha CD, Phillips AG (1992) Extracellular dopamine in the rat striatum during ischemia and reperfusion as measured by in vivo electrochemistry and in vivo microdialysis. Brain Res 591:151-159.

Zeevalk GD, Nicklas WJ, Sonsalla PK (1994) NMDA receptor involvement in two animal models of Parkinson's disease. Neurobiol Aging 15:269-270. 